\title{
AUTUN, Cartulaire de l'Eglise
}

Anatole DE CHARMASSE (éd.), Cartulaire de l'Eglise d'Autun, 2 vol., ParisAutun, 1865-1900 (Documents inédits pour servir à l'histoire de l'Autunois, 1).

Karl Heidecker

\section{OpenEdition}

Journals

Édition électronique

URL : https://journals.openedition.org/cem/2602

DOI : $10.4000 /$ cem.2602

ISSN : 1954-3093

Éditeur

Centre d'études médiévales Saint-Germain d'Auxerre

Référence électronique

Karl Heidecker, "AUTUN, Cartulaire de l'Eglise », Bulletin du centre d'études médiévales d'Auxerre I

BUCEMA [En ligne], Collection CBMA, mis en ligne le 20 mars 2008, consulté le 24 septembre 2022

URL : http://journals.openedition.org/cem/2602 ; DOI : https://doi.org/10.4000/cem.2602

Ce document a été généré automatiquement le 24 septembre 2022.

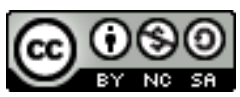

Creative Commons - Attribution - Pas d'Utilisation Commerciale - Partage dans les Mêmes Conditions 4.0 International - CC BY-NC-SA 4.0

https://creativecommons.org/licenses/by-nc-sa/4.0/ 


\section{AUTUN, Cartulaire de l'Eglise}

Anatole DE CHARMASSE (éd.), Cartulaire de l'Eglise d'Autun, 2 vol., ParisAutun, 1865-1900 (Documents inédits pour servir à l'histoire de l'Autunois, 1).

\section{Karl Heidecker}

\section{CARTULAIRE \\ L'ÉGLISE D'AUTUN}

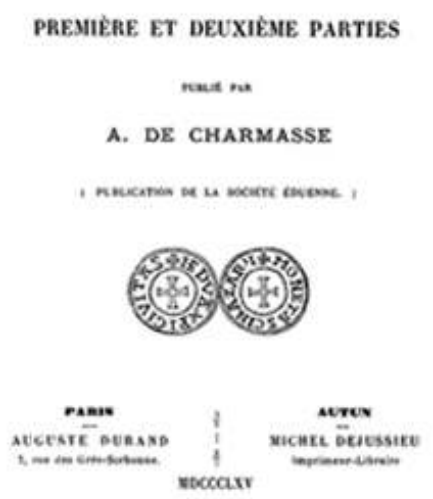

1 L'édition est divisée en trois parties éditées en deux volumes (le vol. 1 comprenant les parties 1 et 2).

2 La première partie contient les 50 actes d'un cartulaire écrit en 1140, aujourd'hui perdu, mais qui a été décrit par Baluze au XVII ${ }^{e}$ siècle. Celui-ci avait dressé un inventaire et transcrit les 10 actes restés inédits jusqu'alors. A. de Charmasse donne 
tous les actes, des années 677-1134, dans l'ordre du cartulaire, c'est-à-dire non de façon chronologique, mais en suivant semble t-il un ordre donné par l'importance des établisseurs d'actes (bulles papales, puis diplômes royaux, puis autres) d'une part, et un rangement régional d'autre part. Les actes ont été édités d'après trois actes originaux, les dix copies de Baluze et douze éditions des XVIe-XVIIe siècles (pour 37 actes) qui se révèlent souvent peu fiables.

3 Les textes ont été tronqués, abrégés, partiellement supprimés et l'orthographe, spécialement celle des noms propres, a été modernisée. L'éditeur n'a pas utilisé tous les actes qui existent encore aujourd'hui sous une forme originale, et il n'a pas consulté d'autres cartulaires (qui donnent souvent des versions fort différentes).

L'acte $\mathrm{n}^{\circ} 34$ a été édité une seconde fois, dans une version meilleure, dans le volume 2 (acte $n^{\circ} 2$ ). Pour la plus grande partie de ces actes, il est préférable de consulter les éditions des Chartes et diplômes des rois de France (pour les actes $\mathrm{n}^{\circ \mathrm{s}}$ 5, 6, 7, 8, 9, 11, 13, 15, 16, 17, 18, 19, 24 et 28), des Monumenta Germaniae Historica (pour les $\mathrm{n}^{\text {os }} 20$ à paraître et 46) et des Papsturkunden 896-1046, éd. H. Zimmermann (pour l'acte $n^{\circ} 48$ ) et dans la base de l'ARTEM où les numéros 12, 23 et 40 sont enregistrés ARTEM 879, 796 et 824.

5 La deuxième partie contient 177 actes des années 880-1299 classés en ordre chronologique, les neuf premiers actes datant des années 880-1122. Parmi ces 177 actes, neuf (les $\mathrm{n}^{\text {os }} 22,23,60,63,104,135,153,159$ et 173) ont été édités d'après des copies des XIVe-XVIIe siècles; ce sont pour la plupart des copies vidimées et notariées assez fiables. Six actes (les $n^{\circ s} 1,2,3,5,26$ et 29 ) ont été édités d'après d'anciennes éditions, souvent peu fiables, alors même que deux d'entre eux (les $n^{\text {os }} 1$ et 2) existent encore aujourd'hui en original. Les actes $n^{\text {os }} 1$ et 7 sont disponibles dans la Base des Originaux de l'ARTEM sous les numéros 4766 et 898; l'acte $\mathrm{n}^{\circ} 2$ dans l'édition des Chartes et diplômes des rois de France. Les 165 autres actes ont été édités d'après leurs originaux. De la même manière, les 18 actes du supplément (pour les années 1215-1288) ont tous été édités d'après leurs originaux.

6 La troisième partie présente dans un ordre chronologique 99 actes des années 897-1300. Les six premiers actes (des années 897-1116) ont été édités d'après un manuscrit du XVIIe siècle, qui avait lui-même repris les actes dans un cartulaire du XII ${ }^{e}$ siècle, et qui contient 63 actes dont la plupart se trouve aussi dans le manuscrit de Baluze ayant servi de base à l'édition de la première partie. L'acte $n^{\circ} 2$ (937-938) est une version plus longue de l'acte déjà édité dans la première partie (vol.1, $\left.\mathrm{n}^{\circ} 34\right)$. Aucun de ces six actes n'a été conservé en original. A partir du n 7 (1194), les actes ont été édités d'après leurs originaux.

- Le texte de ce cartulaire est mis à disposition sur le site web d'ARTeHIS.

\section{INDEX}

Index géographique : France/Autun

Mots-clés : cartulaire 